\title{
The Role of the Tuberculosis (TB) Community in Detecting TB Suspects in Probolinggo Regency, East Java
}

\author{
*Ro'isah ${ }^{1}$, Anies ${ }^{2}$ Mateus Sakundarno ${ }^{3}$, Nur Jazuli ${ }^{4}$ \\ ${ }^{1}$ Doctoral Student of Public Health, Diponegoro University, Semarang, 50275, Indonesia \\ ${ }^{2}$ Faculty of Medicine, Diponegoro University, Semarang, 50275, Indonesia \\ ${ }^{3}$ Epidemiology Department, Faculty of Public Health Diponegoro University, Semarang, 50275, \\ Indonesia \\ ${ }^{4}$ Environmental Health Department, Faculty of Public Health, Diponegoro University, Semarang, \\ 50275, Indonesia
}

\begin{abstract}
Indonesia Indonesia is in the third rank of countries with the highest tuberculosis (TB) globally, with TB case detection still below $70 \%$. The strategy in the TB control program to increase TB case detection is community partnership through the TB community. However, the role of this community in detecting TB suspects has never been reported. This study aimed to determine the role of the TB community in detecting TB suspects in the Probolinggo Regency. This research is descriptive qualitative research. The population was all TB community members is 130 people. The sample was a purposive sampling method, consideration until it met the data saturation, namely 29 respondents. The data were collected employing interviewed sheets, then analyzed with thematic content. Data triangulation by Head of Infectious Diseases, the Probolinggo Regency Health and five people from each TB community at Puskesmas. From the interviews, it was found that 23 people $(79 \%)$ could not invite TB suspects to undergo examination, and 25 people $(86 \%)$ had conducted counselling but were still unable to explain and convince the community of the importance of medical examinations for TB suspects. It is necessary to increase the capacity of TB community members to improve their roles in detecting TB cases.
\end{abstract}

\section{Research Background}

Tuberculosis (TB) is still a public health problem, and new infections emerge every year. Indonesia is the third-highest globally in terms of tuberculosis, where around 326,210 cases have not been detected, and case detection is still below the 70\% target.[1][2][3] TB case finding is an indicator of TB elimination target achievement [4], and finding people with TB symptoms will reduce transmission. [5] For this reason, it requires the involvement of all parties, including government, private sector, and community partnerships, in early TB casefinding activities. [6] Regarding this, the strategy for TB control in Probolinggo Regency involves the community through TB communities to increase TB case detection. 
Referring to the Regulation of the Minister of Health of the Republic of Indonesia Number 67 of 2016, TB control is a health effort that prioritizes promotional, preventive, and curative activities by involving the active participation of the community through community social organizations. [7] The community can participate in changing hygiene and healthy living habits, reducing stigma in the community, forming people who care about tuberculosis treatment, and ensuring that people at risk of TB get tested.

The TB community comprises community social organizations formed by the Public Health Center (Puskesmas) for TB control programs. Based on initial interviews with TB program holders, Probolinggo Regency has formed a TB community since 2017. Its members come from the community consisting of cadres, former TB sufferers, and families. It is hoped that the involvement of these members will make it easier for TB suspects to be examined because they are considered to be closer and more acquainted with the community than health workers. [8]

From its establishment until now, the implementation of the TB community activities is still waiting for instructions from the TB program holders. There is no management in the TB community group, and the participation of members is still lacking. The TB community establishment is based on the Decree of the Head of the Puskesmas as the person in charge, an innovation from each Puskesmas in Indonesia territory.

Besides, this TB community does not have standardization from the government, so that each region forms a TB community as needed. The role of this TB community, among others, is to search for TB suspects using the movement 1-20. It means that every time one TB case is found, an investigation of at least 20 people around it is carried out. Also, counselling is carried out to TB risk communities. Meanwhile, TB case finding among TB suspects and a history of contact with TB sufferers require intensive search [9].

At present, the role of the TB community in Probolinggo Regency in the detection of TB cases has not been reported, and an evaluation of the TB community's participation and involvement has never been conducted. In previous research in China, an institution is tasked with playing an active role in reporting TB cases in its territory. [10] Supposedly, the TB community in Indonesia can carry out its role properly and conduct monitoring and evaluation to find out the community's progress. [11]

Based on the health profile of Probolinggo Regency in 2020, the achievement of TB case detection was still below the national target, which was $65 \%$. In fact, the existence of this TB community is expected to increase TB case detection. Therefore, the researchers are interested in describing the TB community's role in detecting TB suspects. For this reason, this study aimed to determine the role of the TB community in detecting TB suspects in the Probolinggo Regency.

\section{Method}

This study used a qualitative descriptive research design. The research focus was on the role of the TB community in the Probolinggo Regency area. The role here included participation in the implementation of TB community activities in detecting TB suspects. The form of participation by $\mathrm{TB}$ community members is participation in TB community activity meetings and mobilizing other communities for health checks for TB suspects.

The population in this study was all TB community members in the five association areas in Probolinggo Regency. Meanwhile, the sample was the TB community members in Probolinggo Regency, East Java. Determination of the sample was by employing a purposive sampling method based on the researchers' consideration, the data sufficiency, the data saturation, and the information suitability of the TB community members. The research variable was the role of the TB community in detecting TB suspects. Primary data collection 
was to describe the role of the TB community in detecting TB suspects utilizing an interview sheet.

The first interviews were conducted with 29 TB community members: six from TB community at Puskesmas Pajarakan, five from TB community at Puskesmas Kraksaan, six from TB community at Puskesmas Krejengan, six from TB community at Puskesmas Wangkal, and six from TB community at Puskesmas Maron. The data were then validated through data triangulation by one Head of Infectious Diseases, the Probolinggo Regency Health Office, and five people from each TB community at Puskesmas TB program holders responsible for implementing activities. Then, the secondary data on membership, TB community activities, and TB case detection achievements were carried out through the observation method.

The data collection procedure was performed after obtaining research permission. The research team had coordinated with TB program holders by giving invitations to participate in interviews and FGD (focus group discussions). Interviews and discussions took place in each TB community area. Furthermore, an informed consent agreement was given to the respondents for their willingness to participate in the research.

All TB community members who were willing to participate were given free transportation, food, and drinks when they came to the interview location. After the individual interviews were completed, it was followed by an FGD, consisting of 5-6 community members and one facilitator from the TB program holder. Questions comprised: What was your role in finding TB suspects? How was your experience in searching for TB suspects? Have you encountered any obstacles in investigating TB contacts? Do you experience any problems in providing counselling to people suspected of having TB? How were you involved in the TB community activities?

\section{Ethical procedures}

Ethical approval was obtained from the STIKES Hafshawaty Health Institute No. KEPK/264/STIKes-HPXH/IX/2020. Consent was obtained at the beginning, before data collection, to protect the subject and maintain participant confidentiality by giving the name initials.

\section{Data analysis}

Data analysis used thematic content by examining all data from primary data and interview data, examining emerging themes regarding the role of the TB community in detecting TB suspects. How the subjects performed their role in the contact investigation and their role in educating the community suspected of TB were also examined. Researchers identified themes based on transcript data that were read repeatedly about the role of TB community members in detecting TB suspects. Furthermore, primary data and secondary data were presented in the form of narrative text and frequency distribution. [12]

\section{Results}

\subsection{The Profile of the TB Community in Probolinggo Regency}

Probolinggo Regency is part of East Java Province, geographically located on the slopes of the mountains that stretch from west to east, namely Mount Semeru, Argopuro, Lamongan Tengger, and Bromo. Its area is about 169,616.65 Ha, consisting of 24 sub-districts, 325 villages, and 33 Puskesmas. [8] The Puskesmas in the Probolinggo Regency has implemented 
a strategy for TB control in accordance with the Ministry of Health of the Republic of Indonesia in 2016, namely by expanding partnerships with the community in TB case detection through the TB community.

Of the 33 Puskesmas in the Probolinggo Regency, five TB communities were formed: TB community Puskesmas Wangkal, Kraksaan, Krejengan, Pajarakan, dan Maron. Based on interviews with TB program holders, TB communities were formed starting in 2017 in five Puskesmas areas. The TB community formation was an innovation from the Puskesmas under the responsibility of the Probolinggo Regency Health Office. Each TB community had 26 members whom the TB Puskesmas program holder directly elected.

This research was conducted at the TB communities in Probolinggo Regency, with 29 TB community members, $34 \%$ aged $35-42$ years, $86.2 \%$ were female, $48.4 \%$ were junior high school education, and $14 \%$ working as housewives. The TB community members' characteristics are presented in Table 1.

Table. 1. The TB Community Members' Characteristics in Probolinggo Regency

\begin{tabular}{lcc}
\hline \multicolumn{1}{c}{ Characteristics } & $\begin{array}{c}\text { Frequency } \\
\mathbf{n = 2 9}\end{array}$ & Percentage (\%) \\
\hline Age & 6 & 20.7 \\
$19-26$ & 9 & 31.0 \\
$27-34$ & 10 & 34.5 \\
$35-42$ & 3 & 10.3 \\
$43-50$ & 1 & 3.4 \\
$51-58$ & - & - \\
$59-66$ & 29 & 100 \\
Total & & \\
& & \\
Gender & 4 & 13.8 \\
Male & 25 & 86.2 \\
Female & 29 & 100 \\
Total & & \\
\hline Education & 8 & 27.6 \\
Elementary School & 14 & 48.3 \\
Junior High School & 7 & 24.1 \\
Senior High school & - & - \\
College & 29 & 100 \\
Total & & \\
\hline Profession & 12 & 41.4 \\
Student & 14 & 48.3 \\
Housewife & 1 & 3.4 \\
Entrepreneur & 2 & 6.9 \\
Farmer & - & - \\
Total & 29 & 100 \\
& & \\
\hline
\end{tabular}

Based on secondary data from the Probolinggo Regency Health Office, TB cases have increased every year. The following are the case finding achievements from 2017 to March 2021 in Probolinggo Regency in Fig. 1 below: 


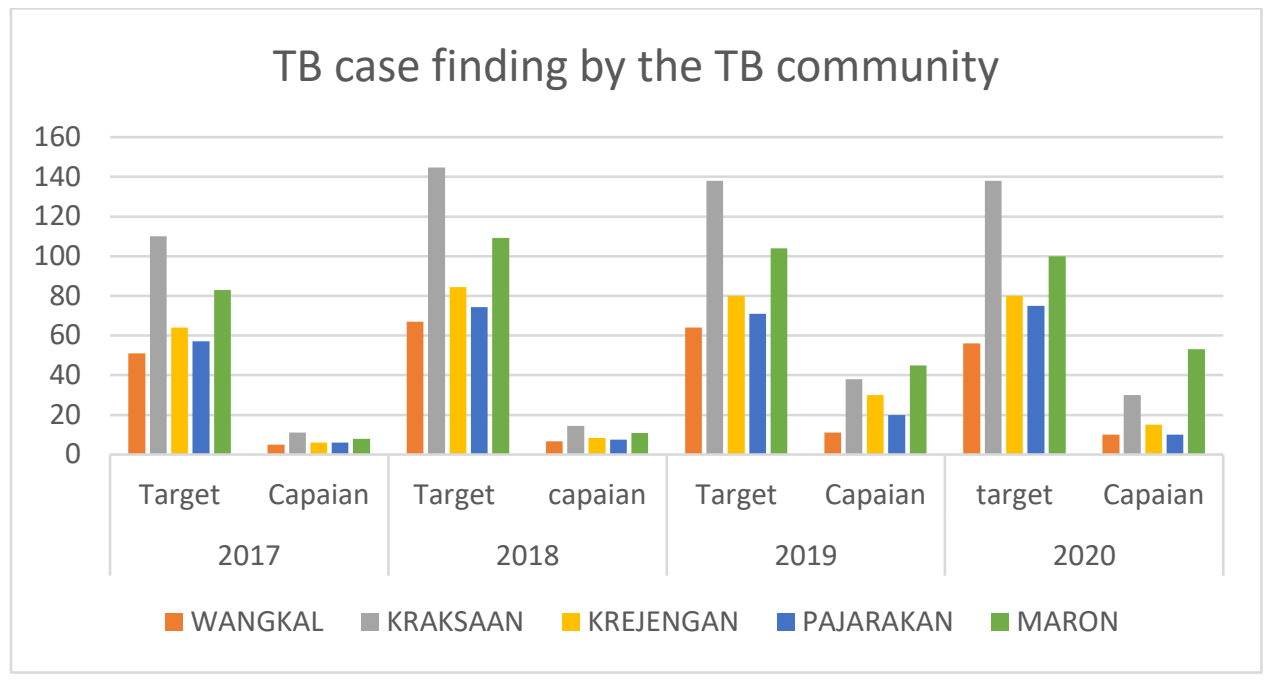

Fig. 1. The Achievements of TB Case Discovery by TB Communities in Probolinggo Regency.

The TB case discovery by the TB community in Puskesmas Wangkal, Kraksaan, Krejengan, Pajarakan, and Maron in the last four years from 2017 to 2020 showed that the achievement of TB case detection had not met the target set.

\subsection{The Role of TB Community in Detecting TB Suspects}

Based on the interviews, there are three themes in this study: the role of the TB community in finding TB suspects in conducting contact investigations, the role in counselling TB suspects, and the role in being involved in TB community meeting activities.

The subject stated that the role in conducting contact investigations was carried out by finding people who had TB symptoms through home visits. A home visit was carried out if one TB patient was found, a search for 20 people around him would be done.

Based on interviews with 29 TB community members regarding their role in detecting TB suspects, it was found that 23 people (79\%) had already investigated TB contacts with home visit activities but had not been able to invite TB suspects to carry out examinations. Meanwhile, six people (20.6\%) had conducted a contact investigation, and TB suspects were willing to do sputum checks.

\subsection{The Role of TB Community in Providing Counselling}

Based on the interview, the subject said that the role in conducting counselling was also carried out when making home visits. The counselling included providing information about TB and the importance of health checks for TB suspects.

In their role in providing counselling, it was found that 25 people $(86 \%)$ had already provided counselling but were still unable to explain and convince the public the importance of health checks for those who cough for more than two weeks because TB is still a stigma, namely embarrassment if suffering from TB disease.

Meanwhile, four people $(13.8 \%)$ had not yet done counselling. At the time of the interview, those who had not conducted any counselling were because every time they invited TB suspects, they were still underestimated; the community still thinks that the community members are not health workers. 


\subsection{The Role of TB Community Members in TB Community Meeting Activities}

Based on interviews related to roles in TB community meeting activities held with budgets from Puskesmas operations, the participation of members in activities was less active. TB community members still came to meetings if coordinated by the TB program holder. A community leader and treasurer have been formed in the TB community, but planning and evaluation of the TB community have not been implemented.

The activities of each meeting were to disseminate TB information by TB program holders and share experiences in finding TB cases. Besides, TB community meetings were only held twice a year because of the budget. Also, not all community members participated actively in meetings because, sometimes, there were family activities, so they could not attend the meetings.

\section{Discussion}

\subsection{The Role of TB Community in Detecting TB Suspects}

Based on the research results on the role of the TB community in detecting TB suspects, it was found that in conducting contact investigations, 23 people $(79 \%)$ had not been able to invite TB suspects to carry out medical examinations. It was probably due to the lack of TB community members' skills in getting TB suspects to do check-ups. Meanwhile, six people $(20.6 \%)$ had conducted a contact investigation, and TB suspects were willing to do sputum checks.

TB case finding is complex and requires resources that require training. In Makassar, Indonesia, the role of the community by involving Aisyiah cadres who cared about TB was still lacking in early detection of TB suspects, the ability to advocate, the ability to mobilize, and the ability to eliminate the stigma of TB sufferers. [10]

TB case finding involving the community may be effective in the search for TB suspects. [4][13] Various community-led organizations in TB case finding are effective and need to be implemented. [4][8][9][14] Previous research has stated that partnerships with the community could improve access to health services in the prevention of tuberculosis. [15][16] This community involvement could improve TB case detection. [5][17] Based on secondary data on the achievement of the TB community in detecting suspects, it was found that the achievements were not according to the target set. It was due to the inability of the TB community to invite TB suspects to carry out health checks, and the community still considered TB to be a stigma that they were embarrassed if their disease was known.

\subsection{The Role of TB Community in Providing Counselling}

In the role of the TB community in providing counselling for those who cough for more than two weeks, it was found that $86 \%$ had conducted counselling but were unable to explain and convince the public of the importance of examining TB suspects. It was because TB is still a stigma, which is a shame if suffering from TB disease. It is consistent with research from the TB patients' life experiences that the delay in identifying TB cases is due to the presence of stigma. [18][9] Other challenges in finding suspects include a lack of training, the presence of stigma, a lack of public awareness about TB, and the inability to convince to carry out a sputum test. [9][14] 
For this reason, the role of community social workers in health can increase the national target for TB case detection by mobilizing the community in health services. [8] The TB community is a social worker is expected to help increase TB case detection; one of its activities is to conduct home visits to search for TB suspects. [19] In accordance with the TB control program to improve community-based health services, an important role is to investigate the home contacts of TB suspects. [20] The role played by the social community with an active case finding approach through home visits accompanied by counselling could improve TB case detection. [9][21]

However, the inability of community members to explain and convince the community suspected of TB, possibly, was due to a lack of knowledge and skills in giving easy-tounderstand TB information to the community. This knowledge and skills can actually be obtained from the activities of each TB community meeting with good activity planning at each meeting. Currently, there is no planning and evaluation of TB community activities.

\subsection{The Role of TB Community Members in TB Community Meeting Activities}

Based on the research results, the role of the TB community in community meeting activities was only carried out twice a year. The meeting activities included socialization about TB, where the participation of community members in the meeting was still less active and still waiting to be coordinated by the TB program holders. In addition of the activities were only socialization about TB, there was no scheduled planning, and there was no active discussion at every meeting between community members.

TB community members meeting activities by sharing experiences among members in discovering TB suspects have been carried out, but not all meeting participants conducted discussions and shared their experiences in finding suspects.

The lack of participation of community members might be due to a lack of leadership role in the TB community, where the TB community evaluation has not been carried out.

Hence, community participation in the search for TB suspects needs to be increased. [14] Leadership in the community organization also needs evaluation and training to support learning. [22]

For this reason, the existence of this TB community is expected to increase the detection of TB cases in the Probolinggo Regency, but the detection of TB cases is still below the national target, namely $65 \%$. It was probably due to the not yet optimal role of the TB community in the Probolinggo Regency and the lack of public awareness of the importance of health checks for TB suspects.

After knowing the role of the TB community, it is expected that the next researcher can determine the proper empowerment for the TB community in detecting TB suspects.

\section{Conclusion}

The role of the TB community in detecting TB suspects has not been optimal because not all TB community members played a role in investigating contacts and counselling for TB suspects. Also, the participation of members was less active in TB community meeting activities. For this reason, it is necessary to increase the capacity of the TB community to detect TB cases. Government involvement is also needed to monitor and evaluate TB community activities.

\section{References}

1. WHO. Monitoring Health For the SDGs. 2020. 
2. WHO. global Tuberculosis Report. World Health Organization. Published by Elsevier $\mathrm{Ltd} / \mathrm{Inc} / \mathrm{BV}$. All rights reserved.; 2016.

3. WHO. Global Tuberculosis Report 2019. World Health Organization; 2019.

4. Burke RM, Nliwasa M, Feasey HRA, Chaisson LH, Golub JE, Naufal F, et al. Articles Community-based active case-finding interventions for tuberculosis: a systematic review. 2021;283-99.

5. Chen J, Qiu Y, Rueda ZV, Hou J, Lu K, Chen L, et al. Role of community-based active case finding in screening tuberculosis in Yunnan province of China. 2019;0:1-12.

6. Mv A, Harries AD, Satyanarayana S, Thekkur P, Shewade HD, Zachariah R. ScienceDirect Review article What is operational research and how can national tuberculosis programmes in low- and middle-income countries use it to end TB ? 2020;7.

7. Kementerian Kesehatan RI. Peraturan Menteri Kesehatan Republik Indonesia Nomor 67 Tahun 2016 tentang Penanggulangan Tuberkulosis. 2016;163. Available from: http://hukor.kemkes.go.id/uploads/produk_hukum/PMK_No.67_ttg_Penanggulangan_ Tuberkolosis_.pdf

8. Garg T, Bhardwaj M, Deo S. Role of community health workers in improving cost efficiency in an active case finding tuberculosis programme: an operational research study from rural. 2020;1-10.

9. Lau LLH, Hung N, Dodd W, Lim K, Ferma JD, Cole DC. SSM - Population Health Social trust and health seeking behaviours : A longitudinal study of a community-based active tuberculosis case finding program in the Philippines. SSM - Popul Heal [Internet]. 2020;12:100664. Available from: https://doi.org/10.1016/j.ssmph.2020.100664

10. Sapar, Salju, M.Risal, Samsinar, M.Zainal, Akbar M. The influence of TB care community cadre's roles on the treatment adherence of tuberculosis (TB) sufferers. Enfermería Clínica. 2020;30(6).

11. Dinas Kesehatan Kabupaten Probolinggo. Profi Dinas Kesehatan Kabupaten Probolinggo. 2020.

12. Norman K Denzin YL. Qualitative REsearch. Sage Publication; 2005.

13. Edward G, Kweku M, Aninagyei E, Duedu KO. International Journal of Infectious Diseases Community-based active tuberculosis case fi nding using a symptom-based screening tool in the Volta Region, Ghana. 2021;102:56-62.

14. Goroh MMD, van den Boogaard CHA, Ibrahim MY, Tha NO, Swe, Robinson F, et al. Factors Affecting Continued Participation in Tuberculosis Contact Investigation in a Low-Income, High-Burden Setting. Trop Med Infect Dis. 2020;5(3):1-13.

15. Joudyian, N., Doshmangir, L., Mahdavi, M., Tabrizi, J.S., Gordeev VS. Public-private partnerships in primary health care: a scoping review. BMC Health Serv Res. 2021;21(1).

16. Manhic I, Jose B, Jones J, Mutaquiha C, Id PZ, Eduardo I, et al. Using community health workers for facility and community based TB case finding: An evaluation in central Mozambique. 2020;371:1-10.

17. Colvin C, Mugyabuso J, Munuo G, Lyimo J, Oren E, Mkomwa Z. Evaluation of community-based interventions to improve $\mathrm{TB}$ case detection in a rural district of Tanzania. 2015;2(2):219-25.

18. Megerso A, Deyessa N, Jarso G, Worku A. Lived experiences of tuberculosis patients and their implications for early tuberculosis case identification and management in pastoralist community setting: a qualitative study in Borena zone, Oromia region of. 2020;1:1-9.

19. Sima BT, Belachew T, Bjune G, Abebe F. Traditional healers ' role in the detection of 
active tuberculosis cases in a pastoralist community in Ethiopia : a pilot interventional study. 2019;1-7.

20. WHO. Health policy and system support to optimize community health worker programmes for HIV , TB and malaria services : an evidence guide. 2020;

21. Id SO, Bonsu F, Adusi-poku Y, Dzata F, Bakker M. Case finding of tuberculosis among mining communities in Ghana. 2021;1-16. Available from: http://dx.doi.org/10.1371/journal.pone.0248718.

22. Puchalski Ritchie LM, Mundeva H, Van Lettow M, Straus SE, Kip E, Makwakwa A. Impact of peer-trainer leadership style on uptake of a peer led educational outreach intervention to improve tuberculosis care and outcomes in Malawi: A qualitative study. BMC Health Serv Res. 2020;20(1):1-10. 